\title{
Facilitation of auditory word recognition
}

\author{
ANITA JACKSON \\ Hatfield Polytechnic, Hatfield, England \\ and \\ JOHN MORTON \\ MRC Cognitive Development Unit, London, England
}

\begin{abstract}
An experiment that investigated facilitation of recognition of spoken words presented in noise is described. Prior to the test session, the subjects either read words or heard them spoken in one of two voices while making a semantic judgment upon them. There was a large effect of auditory priming on word recognition that did not depend upon the voice (male or female) of presentation. There were much smaller, but significant, effects of prior visual experience of the words. The implications of these data for the logogen model are discussed.
\end{abstract}

This paper is concerned with modifications in the logogen model (Morton, 1964, 1969, 1970, 1979a, 1979b). The model is shown in Figure 1. The central feature of the model is the logogen system. This is made of a set of logogens, each one corresponding to a word or morpheme (Murrell \& Morton, 1974). Logogens collect evidence that the corresponding word was presented, this evidence coming both from context and from stimulus information. When the evidence collected by a logogen exceeds a threshold value, the logogen fires and an appropriate code is made available to further stages in the system. The facilitation effects of the prior presentation of a word on its subsequent recognizability were supposed to be due to the activation of a logogen remaining at an elevated level following its firing. The logogen would then require less evidence to fire on subsequent presentation of the stimulus word. In the original system, the logogens took information from both visual and auditory analysis systems. In addition, the same system was responsible for mediating speech production. These two constraints then require that recognition of words presented visually would be facilitated by use of the appropriate logogen under any condition. Thus, following the naming of a picture of a butterfly, the perceptual recognition of the word BUTTERFLY should be facilitated. An experiment by Winnick and Daniel (1970) showed this not to be the case. These authors found that T-scope recognition was facilitated by prior exposure to the stimulus word but was unaffected by other treatments in which the subjects spoke the word without having seen it. These treatments involved either the naming of a picture or the filling of a definition, neither of which led to any advantage to the word in question over a control condition in which no

The experiments reported were run while both the authors were at the MRC Applied Psychology Unit, Cambridge. Reprint requests should be addressed to John Morton, MRC Cognitive Development Unit, 17 Gordon Street, London WCIH OAH, England.

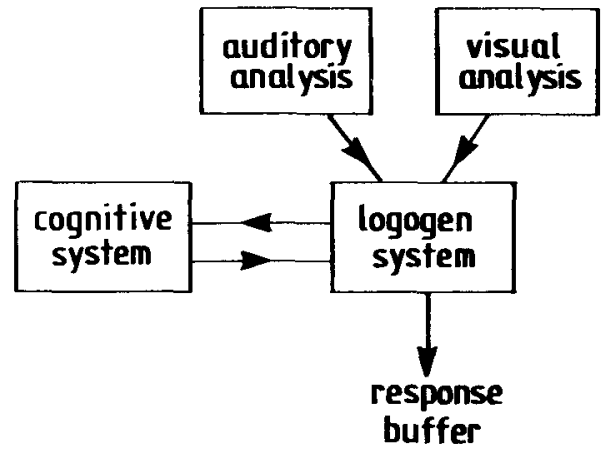

Figure 1. The pre-1979 version of the logogen model.

prior experience was given. The Winnick and Daniel result was so serious in its implications for the logogen model that Clarke and Morton (1983, Experiment 1) carried out a replication. The same results were found. Clarke and Morton concluded that the unified logogen could not be sustained. Instead, there has to be an output lexicon, from which phonological codes are produced, which is separate from the input system. The revised model is shown in Figure 2. Naming a picture would involve the cognitive system and the output logogen system but would leave the input logogen system, the source of the facilitation effects in these experiments, untouched.

In their Experiment 1, Clarke and Morton (1983) also showed that the transfer from reading a handwritten word to the subsequent recognition of a typewritten word was not different from that produced by a typewritten word in the pretraining. This means that the basic identity facilitation effect cannot be due to "visual correspondence" as Winnick and Daniel (1970) had supposed. Rather, the input logogen system must be abstract in some sense and does not differentiate among specific visual forms of stimulus words. Note, however, that this does not mean that the stimulus properties of the words could not be 


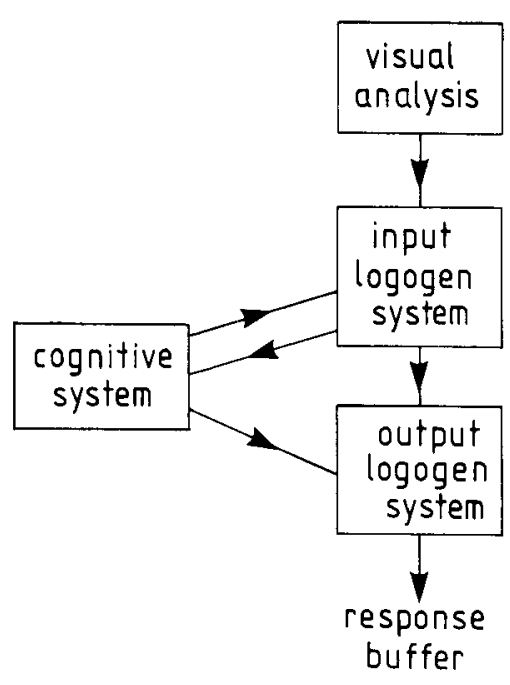

Figure 2. The first modification of the logogen model with separation of input and output lexicons.

registered by some other means, outside the range of the present models (cf. Kolers, 1968, 1975).

Clarke and Morton (1983, Experiments 2 and 3) then addressed the question of cross-modal facilitation. In terms of the model, this is equivalent to asking whether the same input categorization system is involved for both visual and auditory words. The experiments showed that the facilitation from prior auditory experience of a word to subsequent visual recognition, although significant in one of the two experiments, was small compared with visualvisual facilitation. Thus, the process of recognizing and understanding spoken words cannot fully involve the input logogen system responsible for categorizing written words. Note that this statement has something of a definitional quality about it. The term logogen is now being equated, on the input side, with the mechanism responsible for the facilitation effect. It could be that at some stage we may need to separate the mechanism of facilitation from the evidence-gathering function that is also attributed to the logogens. At the moment, however, it is satisfactory to tie them together.

From the limited extent of cross-modal facilitation, we conclude that the auditory input does not pass through the visual input logogen system. Thus, we have to postulate a further system for the categorization of spoken words. There are two main possibilities for the topological organization of the resulting model. The first one of these leads to a symmetrical relationship between the modalities. This is shown in a reduced form in Figure 3. In this configuration, there are no direct connections between the visual and auditory input logogen systems. The second alternative is one in which the output from the visual logogen system passes through the auditory logogen system. This model is shown in outline in Figure 4. There are a number of possible ways in which the subsidiary connections could be organized, but these do not concern us at the moment.
The difference between the models in Figures 3 and 4 is clear. In the case of Figure 3, we would not predict any effect of prior experience in the visual modality on subsequent recognition of auditory stimuli. On the other hand, if the configuration in Figure 4 is correct, we would require that prior visual experience with a word will have an effect equivalent to that of prior auditory experience on the subsequent recognition of the same spoken word.

It is a precondition for the proposed test between the two models that we find a within-modality facilitation over the time intervals of interest. In fact, there is little evidence in the literature for the facilitation in the auditory modality. Such work as there is is with nonsense syllables. Thus, Postman and Rosenzweig (1956) showed that prior frequency of exposure to nonwords affected their recognizability in noise. It is not clear, however, that one can generalize from nonsense syllables to words.

The present experiment, then, had three objectives: (1) to establish within-modality facilitation of auditory

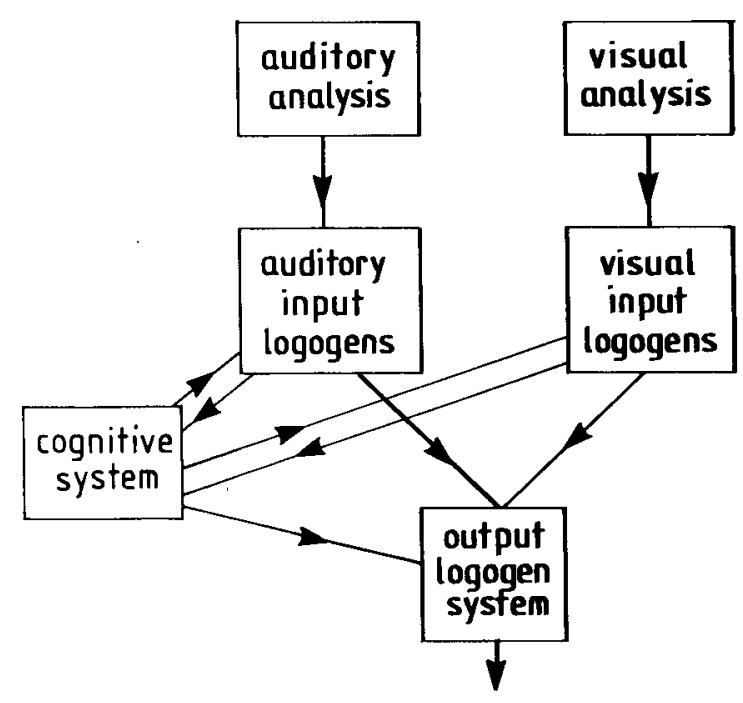

Figure 3. The second modification of the logogen model with independent modality-specific input lexicons.

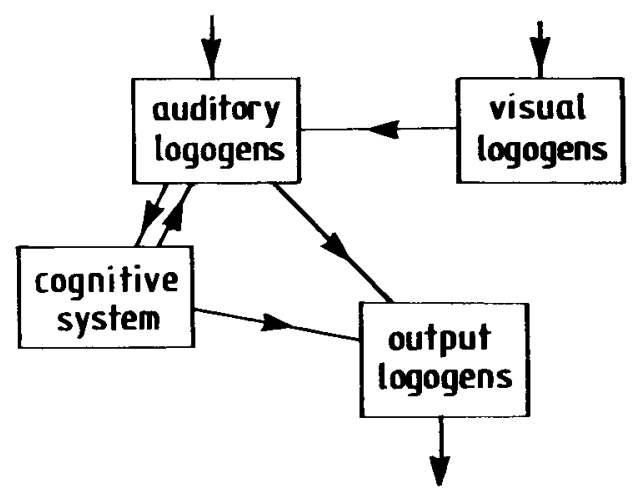

Figure 4. An alternative configuration to Figure 3 in which visual inputs do not have direct access to the cognitive system. 
word recognition; (2) to test whether any within-modality facilitation is specific to a particular voice; (3) to choose between the models in Figures 3 and 4 by testing for visual-auditory facilitation. Note that a preliminary report of this experiment, based on about half the final number of subjects, was given in Morton (1979b).

\section{METHOD}

\section{Design}

The test session consisted of presenting a list of 200 words played in masking white noise. All subject groups except one heard the same tape, the one exception being a control group, for whom the noise level was reduced. The experiment was a separate groups design, with the groups differing according to priming pretreatments. The pretreatments were intended to give the subjects specific experience with the test words. Because of the heterogeneous nature of our subject pool, we could not rely on getting groups that were equated for their hearing ability without having either elaborate screening procedures or unrealistic numbers of subjects. Accordingly, we divided the test words into two sets, one designated experimental and the other baseline (see Stimulus Materials below). In the priming session, then, only the experimental words were presented. The intention was to use a difference score between performance with the experimental words and the baseline words in the test session as an index of the extent of facilitation. In the priming session, the subjects had to make a living/nonliving judgment on the words presented. There were six conditions, each corresponding to subject groups.

1. SAME $(n=19)$ : In the priming session, the 100 experimental words were played spoken clearly in the same (female) voice as that used in the test session. After the 100 words had been judged, the priming tape was played for a second time with the same instructions. Thus, the subjects heard each of the experimental words twice. This was to give the subjects more experience with the experimental words, because a single presentation of the 100 words had not produced sufficient enduring facilitation in a pilot study.

(2) DIFFERENT $(n=20)$ : For this group, the priming tape was recorded in a male voice. It was played twice.

(3) MIXED $(n=18)$ : Half the priming words were recorded in a female voice, and half in a male voice. The voices alternated in a random way in the priming sequence, with the constraint that, in each block of 10 words, 5 were spoken by the female and 5 by the male voice. The resulting tape was played twice.

(4) VISUAL ( $=18$ ): The experimental words were typed onto slides. These were shown to the subjects one at a time under the same instructions as before. The entire sequence of words was shown twice.

(5) CONTROL-1 $(n=20)$ : This subject group had no priming experience. They listened to the same test tape as that played to the first four groups.

(6) CONTROL-2 $(n=18)$ : The stimulus tape was remixed for this group so that the noise level was reduced. There was no priming for these subjects.

\section{Subjects}

Men and women aged between 20 and 60 years were drawn from the A.P.U. subject panel. They were paid for their services. Most of them had had experience with experiments at the A.P.U., although none had participated in listening tests in the previous year. The subjects were tested in groups of 7-12, two groups being assigned to each condition at random.

\section{Stimulus Materials}

The stimulus words were nouns drawn from the full range of frequency in the Kucerra and Francis (1967) tables. There were 100 animate and 100 inanimate or abstract nouns. No homonyms were included. The words were divided into two sets, designated as "experimental" and "control," with equal numbers of animate and inanimate nouns. The sets were matched as closely as possible for word frequency and num- ber of phonemes. These matches were not exact, but since our main comparison was between subject groups and not between word groups, this did not seem to be of primary importance.

\section{Preparation of Materials}

In the priming phase, the experimental words were presented either aurally or visually. In the auditory condition, the words were spoken in a male or a female voice (depending on condition) in a random order at a rate of 1 word per $2.5 \mathrm{sec}$, with the addition of 5 lead-in and 5 lead-out words; the total of 110 words required $4.5 \mathrm{~min}$ to run through. In the visual condition, the experimental words were typed out in uppercase and photographed to produce transparencies of white words on a blue background, which were mounted with special attention given to centering. The slides were loaded into a carousel projector with an attached timer that presented the words at a rate of 1 per $2.5 \mathrm{sec}$ in the same random order as that used in the auditory conditions. The random order of word presentation used in priming bore no relationship to the order used on the test tape.

The test tape consisted of 100 experimental words and 100 control words arranged in such a way that, within each block of 40 words, there were 20 experimental words matched as far as possible for frequency and number of syllables with 20 control words. There were 10 practice words at the start of the tape. The words were spoken in a female voice, and were preceded by the announcement of each trial number: for example, "Trial One," immediately followed by the simultaneous onset of white noise and the relevant word, the white noise enduring until after the word had offset. Both white noise and speech were rerecorded onto the same channel. Words were presented at a rate of 1 per $7.5 \mathrm{sec}$, which gave the subjects sufficient time to write down their responses. The signal-to-noise level in the test tape was calculated in a pilot study such that naive subjects (i.e., they had had no priming experience) achieved a criterion of $30 \%-40 \%$ correct over the 200 words. This tape was used in all conditions except CONTROL-2.

The CONTROL-2 tape differed from the other test tape in its signal-tonoise ratio in that "naive" pilot subjects achieved approximately $50 \%$ correct report over all 200 words.

\section{Apparatus}

In the auditory priming condition, experimental words were presented to subjects binaurally via individual headphones. In the visual priming condition, slides were projected to the whole group of subjects simultaneously on a large screen. In all priming conditions, the subjects were given dummy buttonpress boxes with which to "record" their categorizations of "living" and "nonliving" nouns.

For the test trials, the subjects were also presented with the items binaurally via individual headphones. The subjects were screened from one another.

\section{Procedure}

In the experimental conditions, the subjects were told that they would be participating in two experiments, the first lasting about $10 \mathrm{~min}$ and the second lasting about $40 \mathrm{~min}$. They were further informed that the first experiment (the priming phase) was concerned with the comprehension of words and that they would hear/see a series of nouns that they should categorize as living or nonliving. If the noun was living, they were not to press the button. The subjects were told that they would see the slides/hear the tape twice so that "practice effects could be analyzed."

When this "experiment" had finished, the subjects were asked to put down their "response buttons" and were given response sheets for the "next experiment." They were told that this experiment was concerned with the intelligibility of words in noise, and that they would hear, for example, "Trial One," and then a single word in noise. The subjects were told to "Write down the word you hear as quickly as possible. Sometimes you will not be sure what the word is; in this case write down what you think it is, but if you do not really know, do not guess." Encouragement was given for clear writing and only one response for each trial. They were also told that they would first hear a set of 10 practice trials. There was no suggestion that the two experiments were at all related, and in the postexperiment briefing none of the subjects mentioned 
that they had noticed any relationship. The design of the experiment meant that there was anything between 5 and $30 \mathrm{~min}$ between the presentation of a word in the priming session and its occurrence on the test tape.

In the control conditions, the subjects received the same instructions as for the second part of the experimental condition, and then they went straight into the recognition trials.

Scoring the Subjects' Responses

The subjects' responses in the recognition trials were marked as correct if the base morphemes were correct, for example, "frogs" for "frog"; minor spelling mistakes that preserved the phonetic identity of the word were overlooked.

\section{RESULTS}

Table 1 gives the mean percent correct for the baseline words and the experimental words for the six conditions. It can be seen that there are substantial effects of priming on the experimental words. Unfortunately, there are also apparently large differences in performance on the baseline words in the different priming conditions. It can be seen from Table 1 that the two effects are related. This relationship could be due to either of two reasons. It is possible that our separate groups design led to groups of subjects who were very unbalanced in respect of their ability to comprehend words spoken in noise. It is clear that the range of abilities among subjects is large, as can be seen in the scatter plot in Figure 5. This figure shows the percent correct responses for individual subjects for the two control conditions and the SAME condition with performance on the experimental words plotted against performance on the baseline words. In addition to differentiating among the subjects, it can be seen that performance is better for the baseline words than for the experimental words. Since there had been no prior experience with the experimental words in the control conditions, this indicates that our attempts to equate the two word groups had failed.

The second possible reason for the discrepancies between the groups on the baseline words is that some general factor had been learned that applied to both experimental and baseline words. Both of these factors would be allowed for by an analysis of covariance. It had been for this reason that the CONTROL-2 condition had been run, the idea being that one could deliberately change performance on both kinds of words by manipulating stimulus conditions. The relation between experimental and baseline words should then follow the same function as for the CONTROL-1 words. The other groups, on the other hand, should show a relative improvement on the experimental words if there were any treatment effects.
The data were subjected to an analysis of covariance, adjusting the experimental scores to those found with the baseline words. This analysis gave a significant effect of conditions $[F(5,106)=19.3, p<.001]$. The adjusted means on the experimental words are given in Table 1. The regression of experimental scores on control scores was linear, showing no significant quadratic component. The mean slope of the regression was 0.775 . The regression lines are drawn on Figure 5 for the three conditions shown. There was a negligible reduction in variance if the conditions were allowed different slopes. Condition means and one slope accounted for $67.34 \%$ of the variance. Separate slopes accounted for only $1.4 \%$, and the quadratic component for a further $0.68 \%$. The remaining $30.57 \%$ is attributable to differences between subjects. The min-max estimate of the standard error of the differences between means was 2.237. With 107 degrees of freedom, we then require differences between means of 4.43 for the $5 \%$ level and 5.87 for the $1 \%$ level with twotailed tests. This was used to make a series of planned comparisons between pairs of conditions.

\section{Hypothesis 1: CONTROL-1 and \\ CONTROL-2 were not different}

The difference between the means was 2.56 , which is well below the 5\% level. Remember that the experimental scores were adjusted for the baseline scores. Thus, the higher signal-to-noise ratio in the CONTROL-2 condition, although giving rise to overall better performance, did not discriminate between the two sets of words.

\section{Hypothesis 2: Visual Pretraining \\ Has No Effect}

The difference between the means for VISUAL and CONTROL-1 was 6.2. This difference is significant at the $1 \%$ level. Thus, it appears that there is cross-modal transfer in this experiment. This will be discussed below.

\section{Hypothesis 3: Auditory and Visual Pretraining Are Not Different}

For this comparison, the DIFFERENT condition was used, since any advantage of the SAME condition could be considered to be due to the specific nature of the priming stimuli rather than to the input categorization system. The difference between the means of DIFFERENT and VISUAL was 7.0, which is significant at the $1 \%$ level. Thus, we conclude that there is a modality-specific effect in this experiment.

Table 1

Raw and Adjusted Scores, by Pretraining Condition (Percent Correct)

\begin{tabular}{lccccccc}
\hline & CONTROL-1 & CONTROL-2 & VISUAL & DIFFERENT VOICE & MIXED VOICES & SAME VOICE \\
\hline Number of Subjects & 20 & 18 & 18 & 20 & 18 & 19 \\
Experimental Words & 32.3 & 49.0 & 39.4 & 45.5 & 42.3 & 52.4 \\
Baseline Words & 40.3 & 58.5 & 41.4 & 40.1 & 32.3 & 46.1 \\
Experimental Words* & 34.5 & 37.0 & 40.7 & 47.7 & 50.6 & 50.0 \\
\hline
\end{tabular}

*Adjusted for covariates. 


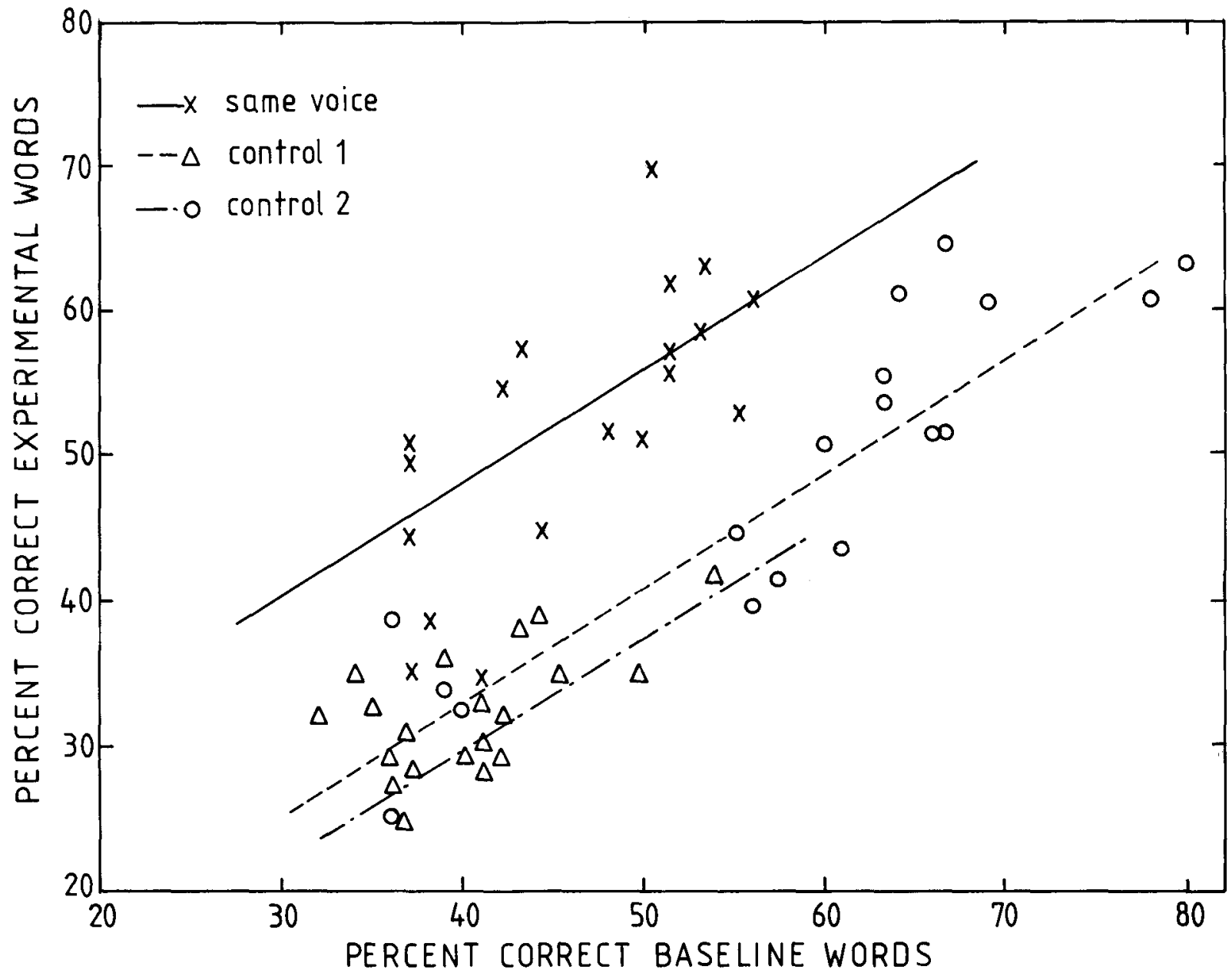

Figure 5. Distribution of scores, by individual subjects, for experimental words and baseline words for the SAME VOICE and the CONTROL conditions.

\section{Hypothesis 4: There Are No Differences Between Pretraining Voices}

If this hypothesis is not true, then we would suppose there to be a stimulus-specific component to the facilitation in addition to a general modality-specific effect. The difference in the means for SAME and DIFFERENT conditions was 2.3. This is well short of the value of 3.71 required for even the one-tailed 5\% level. We might also note that the MIXED VOICE condition was included to allow for the eventuality that there was a voice-specific effect. If there had been, the MIXED condition should give rise to a facilitation intermediate to those in the SAME and DIFFERENT conditions. In fact, it is slightly greater than that in the SAME condition. Thus, there is no evidence that there are differences between the voices. It seems that the modality-specific effect is unrelated to the form of the stimulus.

A further test was carried out on the MIXED condition results to confirm this finding. For each individual word, the number of subjects who correctly recognized it was compared with the equivalent score in the CONTROL- 2 condition. This control was taken because the overall performance on the experimental words was about the same in these two conditions. The words were then divided into two sets on the basis of whether they had occurred in the same or different voice in the pretraining condition. If there is a voice-specific effect, then the same-voice words should be better relative to the control than the different-voice words. The contingency table is given in Table 2. In fact, there is a slight advantage to the different-voice words, but the chi-square is nonsignificant $\left(\chi^{2}=2.41\right)$. A test was also made within subjects. For the MIXED group, the mean percent correct for the words spoken in the same voice was $42.4 \%$, and for the different voice, it was $42.2 \%$. These values have to be compared with those of the control groups. The equivalent values for CONTROL-1 were $32.2 \%$ and $32.4 \%$, respectively, and for CONTROL-2 they were $49.2 \%$ and $48.8 \%$. The $t$ values for the comparisons of differences between voices were well below 1 . We thus have no evidence in favor of separating the voices. We can feel secure that the degree of facilitation caused by prior hearing of a word is independent of the voice in which it was spoken. 
Table 2

Comparison of Performance on Individual Words in the CONTROL-2 and MIXED VOICE Conditions

\begin{tabular}{cccc}
\hline $\begin{array}{c}\text { Voice used } \\
\text { in } \\
\text { Pretraining }\end{array}$ & $\begin{array}{c}\text { Score on } \\
\text { CONTROL-2 } \\
\text { Less Than MIXED }\end{array}$ & $\begin{array}{c}\text { Scores } \\
\text { Equal }\end{array}$ & $\begin{array}{c}\text { Score on } \\
\text { CONTROL-2 }\end{array}$ \\
\hline Same & 12 & 5 & 33 \\
Different & 19 & 5 & 26 \\
\hline
\end{tabular}

In the Clarke and Morton (1983) experiment, handwriting had about as much effect as typewriting on the subsequent recognition of typewritten words. These authors concluded that the visual input logogen system was indifferent to the form of the stimulus. The auditory system appears to share this property.

\section{DISCUSSION}

The data support the kind of model proposed in Figure 3 . There was some facilitation of auditory recognition following visual priming, but it was small compared with the effects of auditory priming. The simplest conclusion is that there are two kinds of facilitation, a modality-specific effect and a central effect.

The modality-specific facilitation is attributed to the input logogen systems in Figure 3. The level of analysis here is limited at one end by the finding of equivalent effects of the different voices. Another constraint is suggested by a result obtained by Kempley and Morton (1982), who showed high facilitation effects from regularly related words (e.g., "reflected" to "reflecting") but no facilitation whatsoever between physically related words (such as "deflecting" to "reflecting") or between irregularly related words (such as "knelt" to "kneeling"). These data establish the level of analysis as morphemic, but with a structural rather than a semantic or syntactic base (otherwise, the irregularly related words would have had an effect).

The central effect leads to the smaller cross-modality facilitation found in the present experiment and in Clarke and Morton (1983). Since there is no evidence to implicate the output systems in facilitation phenomena of this duration, we conceptualize this effect as a property of the cognitive system. The mechanism of this effect is unclear. One option is that it is attributable to the occasional use of "hypotheses" produced on the basis of partial information, as in the theories of Becker (1976), Newbigging (1961), and Savin (1963). Decisions could then be made among alternatives on the basis of a memory record of the priming phase of the experiment. Such operations are imagined as strategic options in addition to the normal logogen operation (see Clarke \& Morton, 1983, for further discussion). Support for this view comes from Ellis (1982) and Gipson (1984), who have succeeded in running experiments similar to the present one, wherein within-modality priming was found but between-modality priming was totally absent. This was done by controlling tightly the subjects' strategies by means of misleading instructions. In addition, subjects were rejected who, on detailed questioning, showed any awareness of the relationship between the two parts of the experiment.

It should be stressed that our conclusions are valid only for the particular task, identification of words in noise, and for a particular time interval (from $5 \mathrm{~min}$ up to $30 \mathrm{~min}$ or more). With other tasks, such as lexical decision, or other time intervals, we need not expect to find the same pattern of data. To give an analogy, Durso and Johnson (1979) reported facilitation of picture naming when the subjects had read aloud the word that named the picture a few seconds earlier. Warren and Morton (1982), on the other hand, found no transfer from words to pictures in a perceptual recognition task over time intervals of 10-45 min, although there was picture-picture facilitation over these intervals. Equally, we have no a priori reason to expect the same patterns of data in perceptual recognition experiments and in recognition memory. The task demands are different and the stimuli are different in these two cases. The differences between the two in the visual modality were shown by Jacoby and Dallas (1981). The final version of the model must be able to make these distinctions clear.

The experiment was stimulated within the context of the logogen model and was designed to decide between alternatives within that framework. Other approaches to word recognition have been discussed elsewhere (Kempley \& Morton, 1982; Morton, 1979b, 1981) in the context of the logogen model. Suffice it to say that any theory that stresses the specific perceptual context of the priming phase (e.g., Kolers, 1968, 1975; Winnick \& Daniel, 1970) will have to find some other mechanism to account for the apparent absence of a voice context effect in the present study.

The model in Figure 3 fails to capture all aspects of the data. We find it necessary to postulate the operation of other mechanisms in order to account for the crossmodality effect. Our conclusion is that the model in Figure 3 is too simple. It is, however, an advance on the original logogen model and has scope outside the experimental paradigm used in the present experiment. Its application to neuropsychology can be found in Morton (1980a, 1980b) and Morton and Patterson (1980).

\section{REFERENCES}

BECKER, C. A. (1976). Allocation of attention during visual word recognition. Journal of Experimental Psychology: Human Perception and Performance, 2, 556-566.

Clarke, R. G. B., MorTon, J. (1983). The effects of priming in visual word recognition. Quarterly Joumal of Experimental Psychology, 35A, 79-96.

Durso, F. T., Johnson, M. K. (1979). Facilitation in naming and categorizing repeated pictures and words. Joumal of Experimental Psychology: Human Learning and Memory, 5, 449-459. 
Ellis, A. W. (1982). Modality-specific repetition: Priming of auditory word recognition. Current Psychological Research, 2, 123-128.

GIPSON, P. (1984). A study of the long-term priming of auditory word recognition. Unpublished doctoral dissertation, University of Cambridge.

JACOBY, L. L., \& DALLAS, M. (1981). On the relationship between autobiographical memory and perceptual learning. Journal of Experimental Psychology: General, 110, 306-340.

KeMPLEY, S. T., \& MORTON, J. (1982). The effects of priming with regularly and irregularly related words in auditory word recognition. British Journal of Psychology, 73, 441-454.

KolERs, P. A. (1968). The recognition of geometrically transformed text. Perception \& Psychophysics, 3, 57-64.

KolERs, P. A. (1975). Memorial consequences of automatized encoding. Journal of Experimental Psychology: Human Learning and Memory, 1, 689-701.

KUČERA, H., \& FrANCIS, W. N. (1967). Computational analysis of presentday American English. Providence, RI: Brown University Press.

MoRTON, J. (1964). A preliminary functional model for language behaviour. International Audiology, 3, 216-225.

MORTON, J. (1969). The interaction of information in word recognition. Psychological Review, 76, 165-178.

MorTon, J. (1970). A functional model for memory. In D. A. Norman (Ed.), Models of human memory. New York: Academic Press.

MoRTON, J. (1979a) Facilitation in word recognition: Experiments causing change in the logogen model. In P. A. Kolers, M. E. Wrolstad, \& H. Bouma (Eds.), Processing of visible language. New York: Plenum.

MORTON J. (1979b). Word recognition. In J. Morton \& J. C. Marshall (Eds.), Psycholinguistic series II. London: Elek Scientific Books.
MorTon, J. (1980a). The logogen model and orthographic structure. In U. Frith (Ed.), Cognitive processes in spelling. London: Academic Press.

MorTon, J. (1980b). Two auditory parallels to deep dyslexia. In M. Coltheart, K. Patterson, \& J. C. Marshall (Eds.), Deep dyslexia. London: Routledge \& Kegan Paul.

MORTON, J. (1981). The status of information processing models of language. Philosophical transactions of the Royal Society of London, B, 295, 387-396.

Morton, J., \& Patterson, K. (1980). A new attempt at an interpretation. In M. Coltheart, K. Patterson, \& J. C. Marshall (Eds.), Deep dyslexia. London: Routledge and Kegan Paul.

MuRRELl, G. A., \& MORTON, J. (1974). Word recognition and morphemic structure. Journal of Experimental Psychology, 102, 963-968.

NEWBIGGING, P. L. (1961). The perceptual redintegration of frequent and infrequent words. Canadian Journal of Psychology, 15, 123-132.

Postman, L., \& Rosenzweig, M. R. (1956). Practice and transfer in the visual and auditory recognition of verbal stimuli. American Journal of Psychology, 69, 209-226.

SAvIN, H. B. (1963). Word-frequency effect and errors in the perception of speech. Journal of the Acoustical Society of America, 35, 200-206.

WARREN, C., \& MORTON, J. (1982). The effects of priming on picture recognition. British Journal of Psychology, 73, 117-129.

WinNICK, W. A., DANIEL, S. A. (1970). Two kinds of response priming in tachistoscopic recognition. Journal of Experimental Psychology, 84, 74-81.

(Manuscript received May 19, 1983; revision accepted for publication May 25, 1984.) 